\title{
Recombinant Nox4 cytosolic domain produced by a cell or cell-free base systems exhibits constitutive diaphorase activity
}

\author{
Minh Vu Chuong Nguyen ${ }^{\mathrm{a}, *}$, Leilei Zhang ${ }^{\mathrm{a}}$, Stanislas Lhomme ${ }^{\mathrm{b}}$, Nicolas Mouz ${ }^{\mathrm{b}}$, Jean-Luc Lenormand ${ }^{\mathrm{c}}$, \\ Bernard Lardy ${ }^{\mathrm{a}}$, Françoise Morel $^{\mathrm{a}}$ \\ ${ }^{a}$ GREPI AGIM FRE 3405 CNRS-UJF, Université Joseph Fourier, Grenoble, France \\ ${ }^{\mathrm{b}}$ PX'Therapeutics, MINATEC/Batiment de Haute Technologie, Grenoble, France \\ ${ }^{\mathrm{c}}$ HumProTher Laboratory, TheReX/TIMC-IMAG UMR 5525 CNRS UJF, Université Joseph Fourier, UFR de Médecine, Domaine de la Merci, 38706 La Tronche, France
}

\section{A R T I C L E I N F O}

\section{Article history:}

Received 13 January 2012

Available online 3 February 2012

\section{Keywords:}

NADPH oxidase Nox4

Cell-free protein expression

Diaphorase activity

Truncated recombinant proteins

\begin{abstract}
A B S T R A C T
The membrane protein NADPH (nicotinamide adenine dinucleotide phosphate) oxidase Nox4 constitutively generates reactive oxygen species differing from other NADPH oxidases activity, particularly in Nox2 which needs a stimulus to be active. Although the precise mechanism of production of reactive oxygen species by Nox 2 is well characterized, the electronic transfer throughout Nox4 remains unclear. Our study aims to investigate the initial electronic transfer step (diaphorase activity) of the cytosolic tail of Nox4. For this purpose, we developed two different approaches to produce soluble and active truncated Nox4 proteins. We synthesized soluble recombinant proteins either by in vitro translation or by bacteria induction. While proteins obtained by bacteria induction demonstrate an activity of $4.4 \pm 1.7 \mathrm{nmol} / \mathrm{min} /$ nmol when measured against iodonitro tetrazolium chloride and $20.5 \pm 2.8 \mathrm{nmol} / \mathrm{min} / \mathrm{nmol}$ with cytochrome $c$, the soluble proteins produced by cell-free expression system exhibit a diaphorase activity with a turn-over of $26 \pm 2.6 \mathrm{nmol} / \mathrm{min} / \mathrm{nmol}$ when measured against iodonitro tetrazolium chloride and $48 \pm 20.2 \mathrm{nmol} / \mathrm{min} / \mathrm{nmol}$ with cytochrome $c$. Furthermore, the activity of the soluble proteins is constitutive and does not need any stimulus. We also show that the cytosolic tail of the isoform Nox4B lacking the first NADPH binding site is unable to demonstrate any diaphorase activity pointing out the importance of this domain.
\end{abstract}

(c) 2012 Elsevier Inc. All rights reserved.

\section{Introduction}

Reactive oxygen species (ROS), comprising superoxide anion and its derivatives, play an essential role both to fight against bacteria invasion in the immune system and to act as signaling molecules in critical cellular events such as oxygen sensing, proliferation and apoptosis. NADPH (nicotinamide adenine dinucleotide phosphate) oxidases or Nox are the major sources of ROS production and include seven members consisting of five Nox (Nox1-Nox5) and two dual oxidases (Duox1 and Duox2). These members are expressed in different types of tissue, and their function, differ from each other. Nox2, also known as gp91phox, is extensively studied and mainly expressed in phagocytic cells. Its dysfunction leads to a specific rare disease named chronic granulomatose disease (CGD). Nox2 forms a stable heterodimer called cytochrome $b_{558}$ with a membrane associated catalytic partner p22phox. Upon activation, cytosolic factors including p40phox, p47phox, p67phox, and Rac1/2 translocate to the plasma mem-

* Corresponding author. Address: Centre Hospitalier Universitaire de Grenoble, Laboratoire d'Enzymologie/DBPC, BP 217, 38043 Grenoble Cedex 9, France.

E-mail address: mvchuong@yahoo.fr (M.V.C. Nguyen). brane to interact with the cytochrome $b_{558}$ [1]. The conformation of Nox2 then switches to an active form [2]. Nox2 C-terminus contains a binding site for a flavin adenine dinucleotide (FAD) and for a NADPH compounds whereas the N-terminus side consists of six transmembrane helices that reside two hemes stabilized by four histidines residues [3]. In an active state, electrons travel from the NADPH to the FAD then through two heme molecules in order to reduce the oxygen leading to the generation of superoxide anion at last [4]. The electronic transfer from the NADPH to the FAD is also called diaphorase activity and has been well described $[5,6]$.

Nox4 is widely expressed, but its role is primordial in kidney tissue $[7,8]$ where it is primary source of ROS production. The dysfunction of Nox4 activity has been linked to the development of disease such as diabetes [9], hypertension [10], atherosclerosis [11], and osteoarthritis [12]. In contrast to Nox2, the presence of regulatory subunits is not necessary for Nox4 activity [13]. Furthermore, unlike the other member of Nox's family, Nox4 activity is constitutive $[7,12,14,15]$. Nevertheless, the electron transfer mechanism of Nox 4 is not well studied.

Since Nox4 activity is unique compared to other Nox in terms of regulation, we decide to characterize the diaphorase activity located in the $\mathrm{C}$ terminus domain of Nox4 which contains the NADPH 
and FAD binding sites. For this purpose, we herein describe two approaches to produce soluble and active recombinant proteins: (1) an Escherichia coli based expression system and (2) an in vitro transcriptional-translational technique. Using these two methods, we are able to characterize a diaphorase activity for the portion of Nox4 and show that this activity is constitutive. We also establish that the first NADPH binding site which is absent in the isoform Nox4B is necessary to initiate the first electronic transfer step.

\section{Materials and methods}

\subsection{Nox4 truncated constructs generation}

The different constructions of Nox 4 were obtained by PCR. The forward primers (5'-GGAATTCTCCATGGTTCACCATCATTTCGGTCATAAGTC-3' for N-Aqc and N-Bqc; 5'-GGATGAGCGGCCGCCCAGTCAC CATCATTTCGGTC-3' for Aqc-C and Bqc-C; 5'-GGAATTCTCCATGGTC TTGCATGTTTCAGGAGGGCTGC-3' for N-1TM; 5'-GGATGAGCGGCCG CGCCTTGCATGTTTCAGGAGGGCTGC-3' for 1TM-C; 5'-GGAATTCTCC ATGGCCTCTACATATGCAATAAGAG-3' for N-2TM, and 5'-GGATGA GCGGCCGCGCCTCTACATATGCAATAAGAG-3' for 2TM-C) were designed to introduce a Ncol site (underlined) or a NotI site (boldface). The reverse primers (5'-GCGTTACTCGAGTCAGCTGAAAGA CTCTTTATTGTATTC-3' for all the $\mathrm{N}$ terminal his-tag constructions or 5'-GCGTTACTCGAGTTGCTGAAAGACTCTTTATTGTATTC-3' for all the $C$ terminal his-tag positions) possess a Xhol site and a stop codon (underline) for the N-terminal his-tag constructions. The truncated Nox4 were directly cloned in PIVEX 2.3MCS, in pIVEX $2.4 \mathrm{NdeI}$ and $\mathrm{pET} 30 \mathrm{~b}$ vectors.

\subsection{Protein extraction}

BL21( $\lambda$ DE3)CodonPlus-RIL bacteria (Stratagen) were induced by $1 \mathrm{mM}$ Isopropyl thiogalactoside (IPTG) at $16{ }^{\circ} \mathrm{C}$ overnight. Bacteria pellets were lyzed by sonication in lysis buffer ( $50 \mathrm{mM}$ Tris pH7.5, $100 \mathrm{mM} \mathrm{NaCl}, 2 \mathrm{mM} \mathrm{MgCl}, 2 \mu \mathrm{g} / \mathrm{ml}$ leupeptin, $2 \mu \mathrm{g} / \mathrm{ml}$ pepstatin, $10 \mu \mathrm{M}$ TLCK or $50 \mathrm{mM}$ Tris $\mathrm{pH} 7.6,500 \mathrm{mM} \mathrm{NaCl}, 10 \mathrm{mM}$ dithiothreitol (DTT), $1 \%$ CHAPS, $2 \mu \mathrm{g} / \mathrm{ml}$ leupeptin, $2 \mu \mathrm{g} / \mathrm{ml}$ pepstatin, $10 \mu \mathrm{M}$ TLCK), and the lysates were centrifuged at $10,000 \mathrm{~g}$ at $4{ }^{\circ} \mathrm{C}$ for $10 \mathrm{~min}$. The supernatant corresponding to the total protein content was collected and subsequently centrifuged at $46,000 \mathrm{~g} 4{ }^{\circ} \mathrm{C}$ for $30 \mathrm{~min}$ to separate the soluble from the insoluble fraction.

\subsection{Inclusion bodies purification}

IPTG induced transformed bacteria were sonicated in lysis buffer A (50 mM Tris pH7.5, $100 \mathrm{mM} \mathrm{NaCl}, 2 \mathrm{mM} \mathrm{MgCl}, 2 \mu \mathrm{g} / \mathrm{ml} \mathrm{leu-}$ peptin, $2 \mu \mathrm{g} / \mathrm{ml}$ pepstatin, $10 \mu \mathrm{M}$ TLCK). The homogenate was centrifuged at $10,000 \mathrm{~g}, 4^{\circ} \mathrm{C}$ for $10 \mathrm{~min}$ and the subsequent supernatant was centrifuged at $46,000 \mathrm{~g}, 4^{\circ} \mathrm{C}$ for $10 \mathrm{~min}$. The resulting pellet was resuspended in buffer $\mathrm{A}$ containing $2 \mathrm{M} \mathrm{NaCl}$ and then centrifuged again. The pellet was resuspended in buffer A supplemented with $2 \%$ triton X-100. A series of centrifugation and pellet resuspension were performed first with buffer A containing $1 \mathrm{M}$ urea and then with buffer A containing $8 \mathrm{M}$ urea and $1 \mathrm{mM}$ glycine. The solution was then centrifuged for the last time, and the supernatant contains the inclusion bodies. A diagram of the procedure is described in Supplementary Fig. S3.

\subsection{Cell-free expression of different Nox4 truncated forms}

Expression tests for each protein were performed using the RTS ${ }^{\text {TM }}$ HY100 (Roche Applied Science) according to the manufacturer's instructions. Different compounds were used to optimize the expression and the solubility (final concentrations: $5 \mathrm{mM}$
Nonidet P40 (NP40), $0.1 \mathrm{mM} n$-dodecyl- $b$-D-maltoside (DDM), $0.1 \mathrm{mM} / 4 \mathrm{mM}$ oxidized/reduced glutathione (GSH/GSSG), and 1:50 dilution GroE chaperone (Roche Applied Science, Ref. $03263690001)$. The reactions were performed for $20-24 \mathrm{~h}$ at $20^{\circ} \mathrm{C}$. At the end of the incubation, the final reaction (total proteins) was centrifuged at $21,400 \mathrm{~g}, 4^{\circ} \mathrm{C}$ for $30 \mathrm{~min}$ to separate the soluble from the insoluble protein fraction. The expression of the proteins at a large scale was performed with RTS ${ }^{\mathrm{TM}}$ HY500 ProteoMaster (Roche Applied Science) in the Proteomaster ${ }^{\mathrm{TM}}$ apparatus at $20{ }^{\circ} \mathrm{C}$ for $24 \mathrm{~h}$ with a $990 \mathrm{rpm}$ shaking speed. The total protein fraction was then centrifuged $\left(21,400 \mathrm{~g}\right.$ at $4{ }^{\circ} \mathrm{C}$ for $\left.30 \mathrm{~min}\right)$, and the supernatant was considered as the soluble fraction.

\subsection{Purification of his-tag recombinant proteins}

The soluble fraction was equilibrated with four column volumes (CV) of buffer A and then loaded onto a column containing an adequate pre-equilibrated resin. The column was washed extensively with $20 \mathrm{CV}$ of buffer $\mathrm{A}+10 \mathrm{mM}$ imidazole, and the proteins were eluted by a gradient of imidazole starting from $100 \mathrm{mM}$ to $1 \mathrm{M}$. The composition of the buffer $\mathrm{A}$ and resin used are indicated below: (1) for inclusion bodies (buffer A: $50 \mathrm{mM}$ Tris pH7.5, $100 \mathrm{mM} \mathrm{NaCl}, 2 \mathrm{mM} \mathrm{MgCl} 2,2 \mu \mathrm{g} / \mathrm{ml}$ leupeptin, $2 \mu \mathrm{g} / \mathrm{ml}$ pepstatin, $10 \mu \mathrm{M}$ TLCK, $8 \mathrm{M}$ urea, $1 \mathrm{mM}$ glycine and resin: Ni-Sepharose ${ }^{\mathrm{TM}} 6$ Fast-Flow (GE-Healthcare)); (2) for soluble fraction obtained from transformed BL21( $\lambda$ DE3)CodonPlus-RIL bacteria (buffer A: $50 \mathrm{mM}$ Tris pH 7.6, $500 \mathrm{mM} \mathrm{NaCl}, 10 \mathrm{mM}$ DTT, $1 \%$ CHAPS, $2 \mu \mathrm{g} / \mathrm{ml}$ leupeptin, $2 \mu \mathrm{g} / \mathrm{ml}$ pepstatin, $10 \mu \mathrm{M}$ TLCK and resin: Ni-NTA); and (3) for soluble proteins obtained by RTS ${ }^{\mathrm{TM}}$ (buffer A: sodium phosphate $150 \mathrm{mM}$ pH 7.4, $300 \mathrm{mM} \mathrm{NaCl}, 20 \mathrm{mM}$ imidazole, 0,1 mM DDM and resin: TALON ${ }^{\circledR}$ Polyhistidine-Tag Purification Resins).

\subsection{Refolding protocol}

Different compounds indicated in Supplementary Table 1 were used to optimize the refolding conditions. These compounds were randomly combined using the SAmBa software (http:// www.igs.cnrs-mrs.fr/samba/) [16] to generate different refolding buffers. The refolding of purified protein solubilized in $8 \mathrm{M}$ urea was realized by a dilution method ( 40 folds) and then centrifuged at $21,400 \mathrm{~g}, 4^{\circ} \mathrm{C}$ for $30 \mathrm{~min}$ to separate the soluble from the insoluble fraction. The soluble fractions were analyzed by Coomassie blue stained SDS-PAGE, and the solubility was evaluated by densitometry analysis of the gel using Scion ${ }^{\circledR}$ program (NIH, USA) in comparison to the amount of proteins diluted with the same procedure in $8 \mathrm{M}$ urea buffer which corresponded to $100 \%$ of solubility. The score obtained for each compound was calculated as follows: the percentages of solubility in which the compound was present were summarized and divided by the number of time this compound appeared. A high score indicated a good solubilization/refolding capacity of the compound.

\subsection{Cell-free system diaphorase activity assay}

The capacity of electron transfer in vitro was evaluated using an adapted protocol previously described [17]. Briefly, 10 pmol of purified proteins was incubated for $5 \mathrm{~min}$ at $4{ }^{\circ} \mathrm{C}$ in PBS buffer containing $10 \mu \mathrm{M}$ FAD (with or without $300 \mu \mathrm{g}$ of cytosol isolated from HEK293E cells) and $100 \mu \mathrm{M}$ INT (iodonitro tetrazolium chloride) or $100 \mu \mathrm{M}$ cytochrome $c$. The reaction was initiated by the addition of $150 \mu \mathrm{M}$ NADPH, and the reduction of these compounds was followed during $30 \mathrm{~min}$ (at $500 \mathrm{~nm}$ for INT, $\varepsilon_{500 \mathrm{~nm}}=$ $11 \mathrm{mM}^{-1} \mathrm{~cm}^{-1}$ or at $550 \mathrm{~nm}$ for cytochrome $c, \varepsilon_{550 \mathrm{~nm}}=$ $\left.21.1 \mathrm{mM}^{-1} \mathrm{~cm}^{-1}\right)$. 


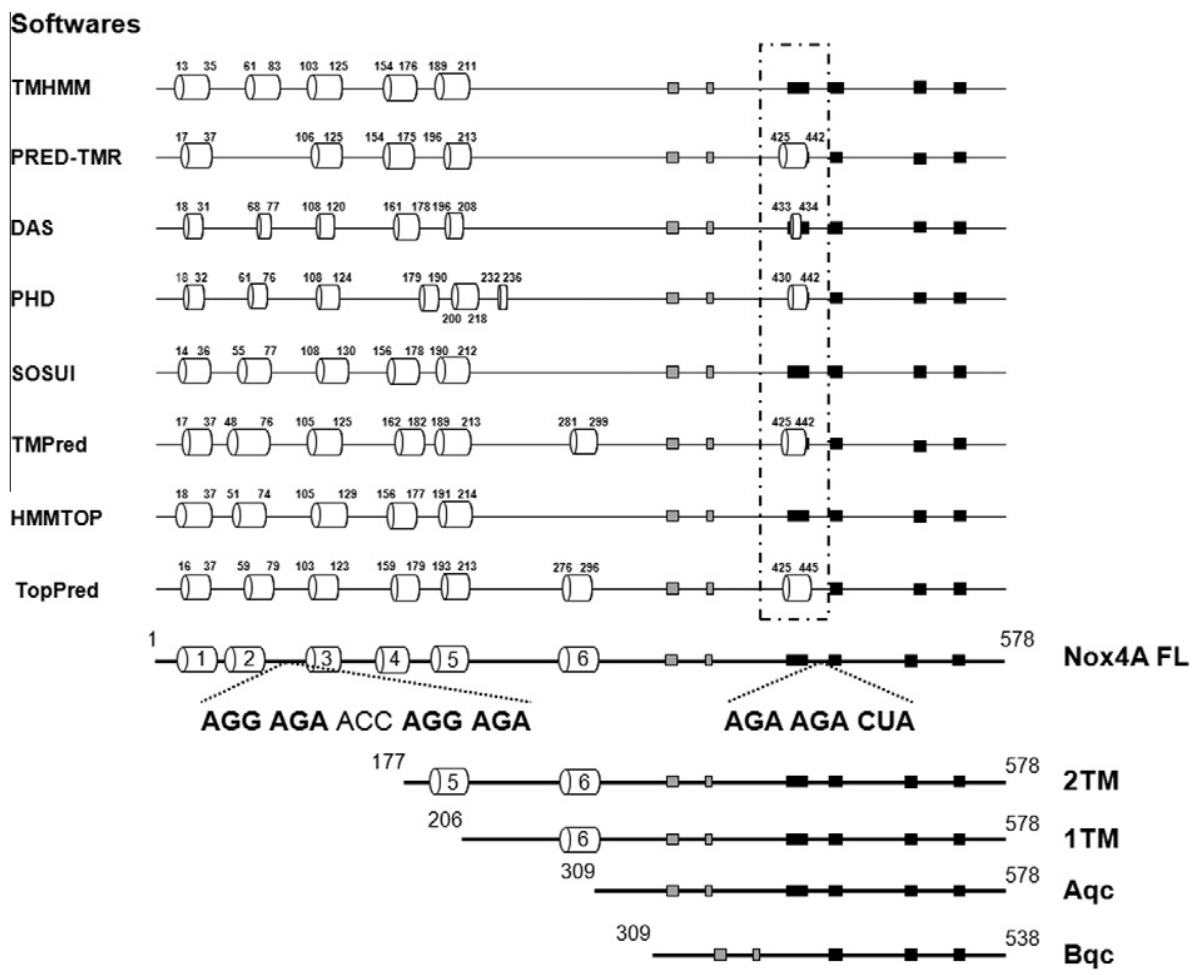

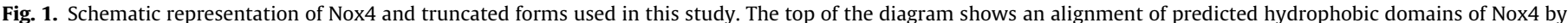

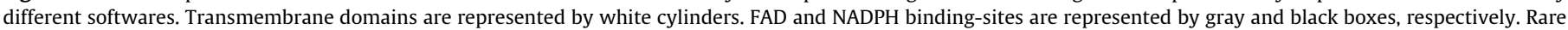
codon sequences are represented at the bottom of the Nox4 full-length scheme. The bottom of the diagram illustrates the truncated Nox 4 proteins used in the study.

\section{Results and discussion}

As well described for Nox2, the diaphorase activity takes place at the cytosolic part of gp91phox $[5,6,18,19]$. This portion of gp91phox protein possesses specific domains dedicated to the binding of NADPH and FAD which are necessary to initiate the electron transfer. An analysis of Nox4 sequence reveals that the C-terminal part of Nox4 also contains two conserved domains (Fig. 1).

In order to characterize the molecular mechanism involved in the establishment of the electron transfer through Nox4, we generated a series of truncated Nox4 proteins containing the NADPH and the FAD domains: 2-TM (177-578), 1-TM (206-578), and Aqc (309-578) derived from the variant Nox4A and Bqc (309-578) from the isoform Nox4B (Fig. 1). One of the NADPH binding domains is missing in the sequence of Nox $4 \mathrm{~B}$ and this isoform has been described as inactive $[12,20]$. Bqc proteins were used to investigate whether the NADPH binding domain was indeed necessary for the diaphorase activity or not. We used two different approaches to express those proteins. The first was an $E$. coli based expression system, and the second was an in vitro transcriptional-translational technique.

\subsection{Expression of Nox4 truncated proteins by bacterial induction}

Constructs described in Fig. 1 with a poly-histidine tag at the Nterminus side were transformed into BL21( $\lambda$ DE3) bacteria. After IPTG induction, we first observed by western blot the presence of the short forms of $\mathrm{N}$-Aqc and $\mathrm{N}$-Bqc proteins in addition of the correct predicted protein size (Fig. 2A). Since rare codons could lead to a premature arrest of the protein synthesis [21,22], we analyzed Nox4 nucleic acid sequence and found that there are two rare codons clusters, AGG-AGA-ACC-AGG-AGA and AGA-AGA-CUA, located at nucleic acids 273 and 1363, respectively (Fig. 1). We were able to avoid the expression of the short forms by using the BL21( $\lambda$ DE3)CodonPlus-RIL bacterial strain which over-expresses tRNA corresponding to those codons (Fig. 2B). However, N-2TM proteins could not be synthesized probably due to the toxicity of the over-expression of membrane proteins by bacteria [23].

We next evaluated the solubility of the synthesized protein and unfortunately found that $\mathrm{N}$-Aqc proteins were totally insoluble (Fig. 2C) as previously reported for Nox2 [18]. An analysis of the hydrophobic properties of Nox4 protein revealed a high hydrophobic domain at the first NADPH binding site (Fig. 1). To counter-balance the negative effect of the hydrophobicity on the solubility of the protein, we designed an approach in two steps. We first purified inclusion bodies of $\mathrm{N}$-Aqc as described in Supplementary Fig. S3 and performed an extensive screening of refolding conditions. The screening process was described in the method section, and an example is presented in Supplementary Fig. S2. Several sets of refolding experiments were necessary to find out the best conditions. Data from refolding experiments revealed that a basic solution with $\mathrm{pH}$ greater than 9 was important to solubilize/refold the denaturated protein as compared to that with $\mathrm{pH}$ 7.4. More interestingly, the NVoy polymer (NV10) and CHAPS at pH 7.4 also had a positive effect on the refolding (Fig. 2D). Based on these results, we hypothesized that lysing directly induced bacteria with the previously determined optimal refolding buffer may favor toward a direct solubilization of the proteins and avoid the initial inclusion bodies purification step. Indeed, we were able to obtain soluble proteins when induced bacteria were lysed in a buffer containing 1\% CHAPS (Fig. 2E).

\subsection{In vitro expression of Nox4 truncated proteins by cell-free system}

Unlike cytosolic proteins, expression of functional membrane protein remains challenging. Difficulties are mainly related to 


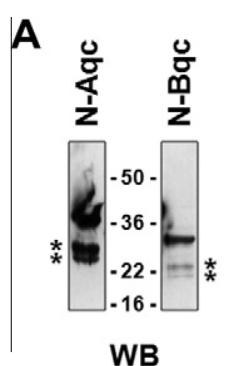

D

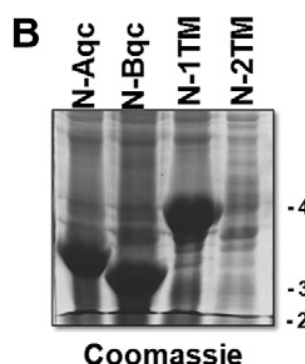

Coomassie

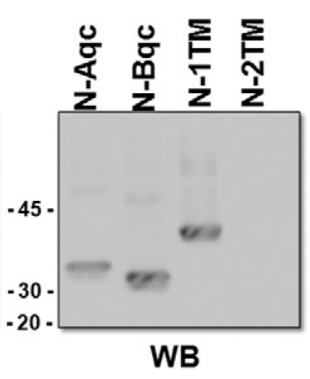

E

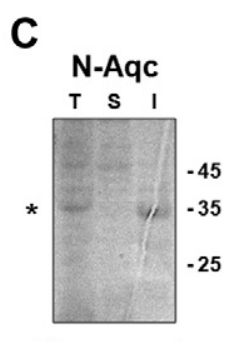

Coomassie

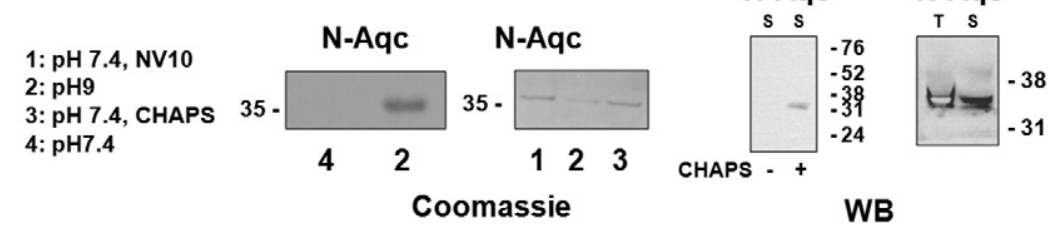

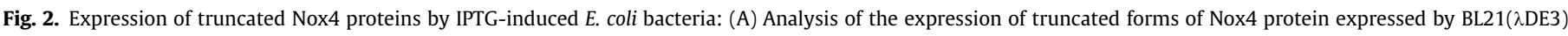

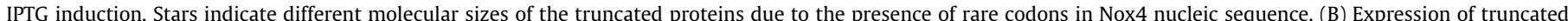

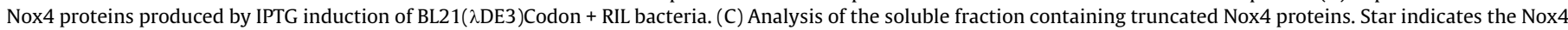

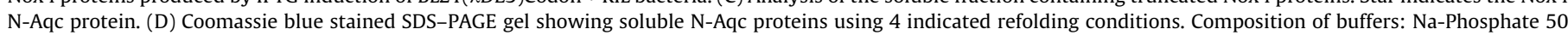

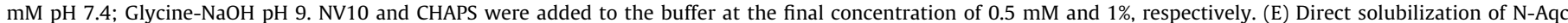
proteins in the lysis buffer containing CHAPS as detergent. WB, western blot uses a monoclonal anti-histidine antibody. T, total; I, insoluble; and S, soluble.

cellular toxicity, misfolding, and insolubility because they lead to low yield and nonfunctional proteins when produced in bacteria. Cell-free expression system has emerged as a powerful alternative to cell-base expression systems to produce and study membrane proteins [24]. We take advantage of this technology to synthesize truncated Nox4 proteins. Using standard synthesis conditions provided by the manufacturer without additives, we are able to express all the truncated proteins including the 2TM protein which cannot be synthesized through the cell base system. Nevertheless, the expression levels are uneven and proteins are barely soluble (Fig. 3, condition A).

We then optimized conditions to obtain soluble proteins by adding the chaperone GroE, the redox couple GSH/GSSG and detergents like Nonidet P40 (NP40) and DDM [25]. Our results show that all parameters play an important role to obtain soluble proteins. For example, the position of the poly-histidine influences the amount of proteins produced as well as its solubility (Fig. $31 \mathrm{TM}$, $\mathrm{E}, \mathrm{F}$, and $\mathrm{G}$ ). Interestingly, the use of the detergent DDM favors toward a better solubility of all constructs contrasting with the addition of NP40 which, in some cases, annihilated the production of soluble proteins (Fig. 3 Bqc and 2TM, E and G). Furthermore, the addition of GroE and GSH/GSSG to DDM increases the solubility of all the truncated proteins (Fig. 3C and D versus B).

Nevertheless, a higher concentration of DDM leads to a loss of the solubility without affecting the total amount of proteins produced (Supplementary Fig. S1A). Although FAD is a natural substrate, it does not significantly increase the solubility (Supplementary Fig. S1B). Finally, based on our results, we find a common optimized condition for the synthesis of all constructs: $0.1 \mathrm{mM}$ of DDM, GroE and $0.1 \mathrm{mM} / 4 \mathrm{mM}$ of GSH/GSSG. As previously described, we observed additional shorter protein bands only with the Nter tag for the proteins 2TM and 1TM, but not with the Cter tag (Fig. 3B). This phenomenon is particularly noticeable for the full length Nox4 Nter tagged protein (Fig. 3A). We, therefore, choose to use the C-terminal tagged proteins to eliminate the interferences mediated by the rare codons. Indeed, the purification

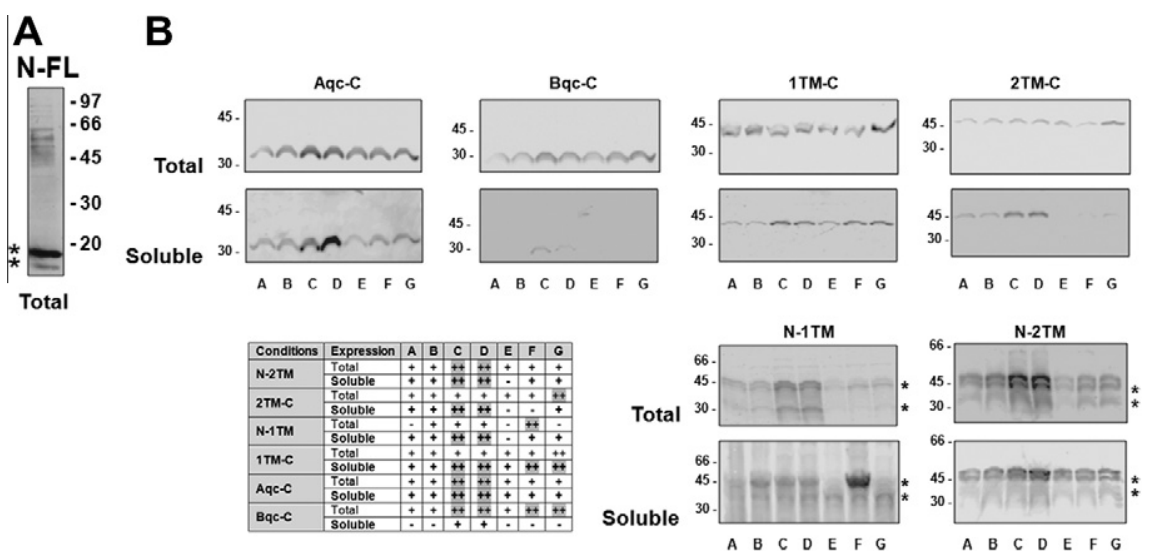

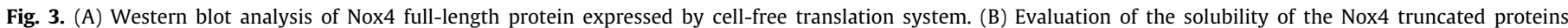

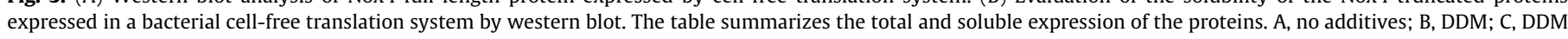

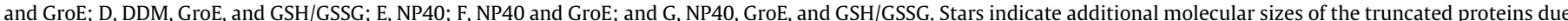

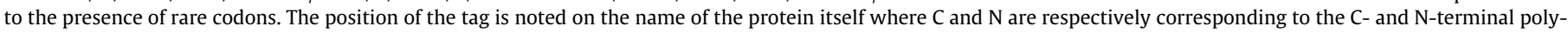
histidine tag. A monoclonal anti-histidine antibody was used. 
A
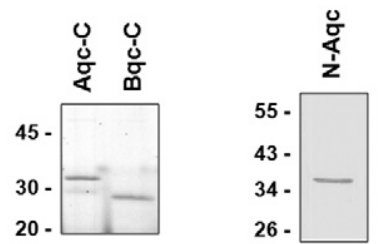

C

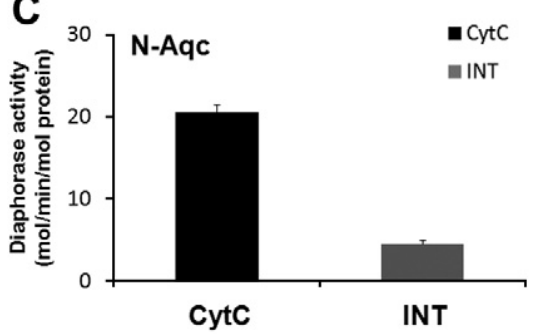

B

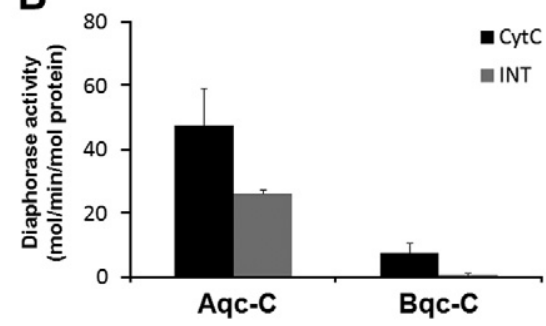

D

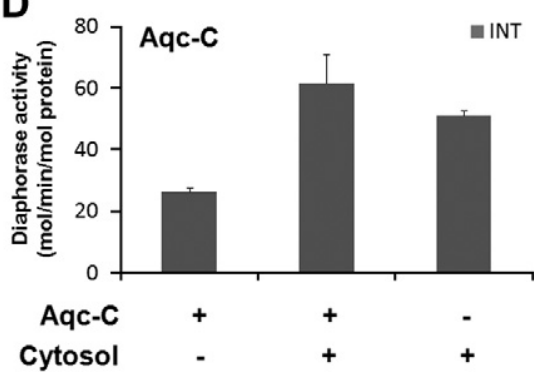

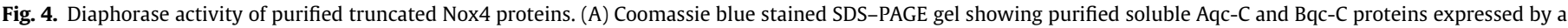

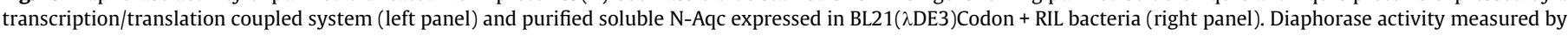

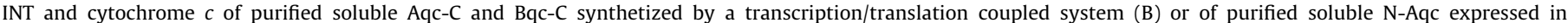

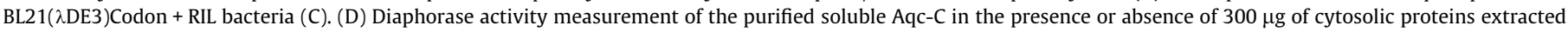
from HEK293 cells.

of proteins by the Cter poly-histidine tag retains only the fulllength form since the tag is missing in the uncompleted translated proteins.

\subsection{Diaphorase activity of Nox4 truncated proteins}

Next, we over-expressed Aqc and Bqc proteins in large scale following the optimized conditions obtained previously. The amount of Aqc proteins obtained is $9 \mu \mathrm{g} / \mathrm{mL}$ of the reaction mixture for the cell-free expression system compared to $0.9 \mu \mathrm{g} / \mathrm{mL}$ of the bacterial culture media for the cell-based system. Purified soluble proteins (Fig. 4A) were tested for the diaphorase activity.

The diaphorase activity of these proteins was measured by two electron acceptors: INT ( $p$-iodonitrotetrazolium) and cytochrome $c$. The values of the specific diaphorase activity for the protein Aqc obtained by RTS are $26 \pm 2.6 \mathrm{nmol} / \mathrm{min} / \mathrm{nmol}$ for INT and $48 \pm 20.2 \mathrm{nmol} / \mathrm{min} / \mathrm{nmol}$ for cytochrome $c$ (Fig. 4B). We then compared these values to the turnover rate of the protein Aqc purified from the IPTG induced bacteria that are $4.4 \pm 1.7 \mathrm{nmol} / \mathrm{min} / \mathrm{nmol}$ for INT and $20.5 \pm 2.8 \mathrm{nmol} / \mathrm{min} / \mathrm{nmol}$ for cytochrome $c$ (Fig. 4C).

We observe that the electron acceptor cytochrome $c$ gives a higher rate for both proteins. Furthermore, the protein Aqc produced by a cell-based system has a lower specific activity compared to the protein synthesized by the cell-free technology. This difference may be due to a distinct folding state of the active proteins. Indeed, in the case of the cell-free based system, the direct contact of the detergent DDM and the chaperone GroE during the protein synthesis process may have provided a better folding environment. As expected, Bqc is unable to reduce any two electronic acceptors, consistent with our previous studies showing that the isoform Nox4B is inactive [12].

Unlike Nox2, the diaphorase activity of Aqc is constitutive, and the addition of cytosolic factors is not necessary to reduce the electron acceptors [19]. Using two different methods of protein synthesis, we demonstrate that the cytosolic domain of Nox4 is responsible for Nox4 constitutive activity. Other authors using a similar portion of the C-terminal part of Nox4 have made the same observations $[26,27]$.
Nevertheless, a disparity in the turnover activity value is noticed. For instance, a turnover of $100 \mathrm{~min}^{-1}$ was observed by Jackson et al. whereas Nisimoto and his colleagues found a diaphorase activity of $160 \mathrm{~min}^{-1}$ when they measured with the cytochrome $c$. The difference observed in both studies may be due to different tags usage and buffer composition. To find out whether Nox4 diaphorase activity could be stimulated by unknown cytosolic components or not, we measure the turnover rate of Aqc in the presence of cytosol extracted from HEK293 cell. We choose HEK293 cells because they express endogenously Nox4. As shown in Fig. 4D, the addition of the cytosol extract does not enhance Aqc activity. Herein, we describe in this study two different optimized methods to produce soluble and active truncated Nox4 proteins. The first method is based on the refolding of insoluble proteins whereas the second is based on a direct folding of the proteins during the translation process. Although the refolded truncated proteins are fully functional, their diaphorase activity has a lower turnover number compared to the folded proteins synthesized by a cell-free system.

Furthermore, the yield obtained by the cell-free expression system is 10 times higher. Our results show that the non-cell-base expression system is more suitable to produce functional Nox4 proteins. We have also demonstrated that the C-terminal domain of Nox4 is capable of generating a constitutive diaphorase activity. This spontaneous transfer of electrons from NADPH to FAD is independent of cytosolic factors isolated from HEK293 cells. We also prove that the isoform Nox4B is unable to initiate the first electronic transfer step. In conclusion, this approach could extend to constitute a powerful tool to characterize step-by-step the electronic transfer mechanism throughout Nox4 protein as well as other NADPH oxidases.

\section{Acknowledgments}

This work was supported by grants from the Ministère de l'Enseignement supérieur de la recherche et technologie, Paris, France; the CNRS Institute; the Association pour la Recherche contre le Cancer (ARC), Paris, France; the Région Rhône-Alpes, programme 
ARCUS, France/Chine 2007-2008, Programme Emergence 20032006; the CGD Research Trust 2006-2007, UK; the Groupement des Entreprises Françaises de la Lutte contre le Cancer, délégation de Grenoble; the UFR de Médecine, Université Joseph Fourier, Grenoble; and the Direction Régionale de la Recherche Clinique, Centre Hospitalier Universitaire, Grenoble.

\section{Appendix A. Supplementary data}

Supplementary data associated with this article can be found, in the online version, at doi:10.1016/j.bbrc.2012.01.136.

\section{References}

[1] F. Morel, J. Doussiere, P.V. Vignais, The superoxide-generating oxidase of phagocytic cells. Physiological, molecular and pathological aspects, Eur. J. Biochem. 201 (1991) 523-546.

[2] M.H. Paclet, A.W. Coleman, S. Vergnaud, F. Morel, P67-phox-mediated NADPH oxidase assembly: imaging of cytochrome $b_{558}$ liposomes by atomic force microscopy, Biochemistry 39 (2000) 9302-9310.

[3] K.J. Biberstine-Kinkade, F.R. DeLeo, R.I. Epstein, B.A. LeRoy, W.M. Nauseef, M.C. Dinauer, Heme-ligating histidines in flavocytochrome $b(558)$ : identification of specific histidines in gp91(phox), J. Biol. Chem. 276 (2001) 31105-31112.

[4] A.R. Cross, A.W. Segal, The NADPH oxidase of professional phagocytesprototype of the NOX electron transport chain systems, Biochim. Biophys. Acta 1657 (2004) 1-22.

[5] I. Pessach, T.L. Leto, H.L. Malech, R. Levy, Essential requirement of cytosolic phospholipase $\mathrm{A}(2)$ for stimulation of NADPH oxidase-associated diaphorase activity in granulocyte-like cells, J. Biol. Chem. 276 (2001) 33495-33503.

[6] I. Pessach, Z. Shmelzer, T.L. Leto, M.C. Dinauer, R. Levy, The C-terminal flavin domain of gp91phox bound to plasma membranes of granulocyte-like X-CGD PLB-985 cells is sufficient to anchor cytosolic oxidase components and support NADPH oxidase-associated diaphorase activity independent of cytosolic phospholipase A2 regulation, J. Leukoc. Biol. 80 (2006) 630-639.

[7] M. Geiszt, J.B. Kopp, P. Varnai, T.L. Leto, Identification of renox, an NAD(P)H oxidase in kidney, Proc. Natl. Acad. Sci. USA 97 (2000) 8010-8014

[8] Y. Gorin, K. Block, J. Hernandez, B. Bhandari, B. Wagner, J.L. Barnes, H.E. Abboud, Nox4 NAD(P)H oxidase mediates hypertrophy and fibronectin expression in the diabetic kidney, J. Biol. Chem. 280 (2005) 39616-39626.

[9] K. Mahadev, H. Motoshima, X. Wu, J.M. Ruddy, R.S. Arnold, G. Cheng, J.D. Lambeth, B.J. Goldstein, The NAD(P)H oxidase homolog Nox4 modulates insulin-stimulated generation of $\mathrm{H}_{2} \mathrm{O}_{2}$ and plays an integral role in insulin signal transduction, Mol. Cell. Biol. 24 (2004) 1844-1854.

[10] T. Akasaki, Y. Ohya, J. Kuroda, K. Eto, I. Abe, H. Sumimoto, M. Iida, Increased expression of gp91phox homologues of $\mathrm{NAD}(\mathrm{P}) \mathrm{H}$ oxidase in the aortic media during chronic hypertension: involvement of the renin-angiotensin system, Hypertens. Res. 29 (2006) 813-820.

[11] D. Sorescu, D. Weiss, B. Lassegue, R.E. Clempus, K. Szocs, G.P. Sorescu, L. Valppu, M.T. Quinn, J.D. Lambeth, J.D. Vega, W.R. Taylor, K.K. Griendling,
Superoxide production and expression of nox family proteins in human atherosclerosis, Circulation 105 (2002) 1429-1435.

[12] L. Grange, M.V. Nguyen, B. Lardy, M. Derouazi, Y. Campion, C. Trocme, M.H Paclet, P. Gaudin, F. Morel, NAD(P)H oxidase activity of Nox4 in chondrocytes is both inducible and involved in collagenase expression, Antioxid. Redox Signal. 8 (2006) 1485-1496.

[13] K.D. Martyn, L.M. Frederick, K. von Loehneysen, M.C. Dinauer, U.G. Knaus, Functional analysis of Nox4 reveals unique characteristics compared to other NADPH oxidases, Cell. Signal. 18 (2006) 69-82.

[14] L. Serrander, L. Cartier, K. Bedard, B. Banfi, B. Lardy, O. Plastre, A. Sienkiewicz, L. Forro, W. Schlegel, K.H. Krause, NOX4 activity is determined by mRNA levels and reveals a unique pattern of ROS generation, Biochem. J. 406 (2007) 105114.

[15] L. Zhang, M.V. Nguyen, B. Lardy, A.J. Jesaitis, A. Grichine, F. Rousset, M. Talbot M.H. Paclet, G. Qian, F. Morel, New insight into the Nox4 subcellular localization in HEK293 cells: first monoclonal antibodies against Nox4 Biochimie 93 (2011) 457-468.

[16] S. Audic, F. Lopez, J.M. Claverie, O. Poirot, C. Abergel, SAmBA: an interactive software for optimizing the design of biological macromolecules crystallization experiments, Proteins 29 (1997) 252-257.

[17] S. Berthier, M.H. Paclet, S. Lerouge, F. Roux, S. Vergnaud, A.W. Coleman, F. Morel, Changing the conformation state of cytochrome $b 558$ initiates NADPH oxidase activation: MRP8/MRP14 regulation, J. Biol. Chem. 278 (2003) 2549925508.

[18] C.H. Han, Y. Nisimoto, S.H. Lee, E.T. Kim, J.D. Lambeth, Characterization of the flavoprotein domain of gp91phox which has NADPH diaphorase activity, J. Biochem. 129 (2001) 513-520.

[19] B. Marques, L. Liguori, M.H. Paclet, A. Villegas-Mendez, R. Rothe, F. Morel, J.L. Lenormand, Liposome-mediated cellular delivery of active gp91(phox), PLoS One 2 (2007) e856.

[20] P. Goyal, N. Weissmann, F. Rose, F. Grimminger, H.J. Schafers, W. Seeger, J Hanze, Identification of novel Nox4 splice variants with impact on ROS levels in A549 cells, Biochem. Biophys. Res. Commun. 329 (2005) 32-39.

[21] K. Wada, Y. Wada, F. Ishibashi, T. Gojobori, T. Ikemura, Codon usage tabulated from the GenBank genetic sequence data, Nucleic Acids Res. 20 (Suppl.) (1992) 2111-2118.

[22] R.A. Spanjaard, J. van Duin, Translation of the sequence AGG-AGG yields 50\% ribosomal frameshift, Proc. Natl. Acad. Sci. USA 85 (1988) 7967-7971.

[23] B. Miroux, J.E. Walker, Over-production of proteins in Escherichia coli: mutant hosts that allow synthesis of some membrane proteins and globular proteins at high levels, J. Mol. Biol. 260 (1996) 289-298.

[24] F. Junge, S. Haberstock, C. Roos, S. Stefer, D. Proverbio, V. Dotsch, F. Bernhard, Advances in cell-free protein synthesis for the functional and structura analysis of membrane proteins, Nat. Biotechnol. 28 (2011) 262-271.

[25] C. Klammt, D. Schwarz, K. Fendler, W. Haase, V. Dotsch, F. Bernhard, Evaluation of detergents for the soluble expression of alpha-helical and beta-barrel-type integral membrane proteins by a preparative scale individual cell-free expression system, FEBS J. 272 (2005) 6024-6038.

[26] H.M. Jackson, T. Kawahara, Y. Nisimoto, S.M. Smith, J.D. Lambeth, Nox4 B-loop creates an interface between the transmembrane and dehydrogenase domains, J. Biol. Chem. 285 (2010) 10281-10290.

[27] Y. Nisimoto, H.M. Jackson, H. Ogawa, T. Kawahara, J.D. Lambeth, Constitutive NADPH-dependent electron transferase activity of the Nox4 dehydrogenase domain, Biochemistry 49 (2010) 2433-2442. 